\title{
Investigation of the Mechanism of the Reaction between Atomic Oxygen Radical Anion and Benzene
}

\author{
Yingguo Zhao, Xiaoguo Zhou*, Feng Yu, Jinghua Dai, Shilin Liu
}

Hefei National Laboratory for Physical Sciences at the Microscale, Department of Chemical Physics, University of Science and Technology of China, Hefei 230026, P. R. China

\begin{abstract}
The reaction mechanism between atomic oxygen radical anion and benzene has been investigated using the density functional theory (DFT). Geometries of the reactants, products, complexes, and transition states involved have been optimized at the $\mathrm{B} 3 \mathrm{LYP} / 6-31+\mathrm{G}(d, p)$ level, and their vibrational frequencies and zero-point energies (ZPEs) have been calculated subsequently at the same level. The multichannel pathways, e.g. the $\mathrm{H}$ atom abstraction, oxide ion formation, $\mathrm{H}_{2}^{+}$transfer, and proton transfer, are confirmed by the calculated potential energy surface of this reaction. Based on the G2MP2 energies, a reasonable description has been proposed qualitatively to explain the inconsistency of previous experimental conclusions.
\end{abstract}

Key Words: Atomic oxygen radical anion; Benzene; Reaction mechanism

Oxide anions play an important role in ionospheric ionic chemistry, stratospheric ionic chemistry, and liquid-phase chemical reactions ${ }^{[1-4]}$, which can be generated from the ionic reactions between atomic oxygen-radical anion $\left(\mathrm{O}^{-}\right)$and neutral molecules. These reactions are very significant in organic chemistry, biochemistry, catalysis, and so on ${ }^{[1-5]}$. For example, reactions between $\mathrm{O}^{-}$and hydrofluorocarbons (HFCs) are related to the concentration of pollutants such as HFCs in the aerosphere ${ }^{[6,7]}$. Thus, it is necessary to investigate these reactions extensively for atmospheric chemistry, radiation chemistry, and biochemistry. Moreover, these reactions will give insight into synthesis of organic intermediate anions and mechanisms of liquid-phase chemical reactions.

Chemical kinetics demonstrates that there are four possible product channels for reactions between $\mathrm{O}^{-}$and neutral organic molecules as follows:

$$
\begin{array}{rlrrr}
\mathrm{O}^{-}+\mathrm{RH} & \rightarrow \mathrm{R}+\mathrm{OH}^{-} & (1) & & \mathrm{H} \text { abstraction } \\
& \rightarrow \mathrm{RO}^{-}+\mathrm{H} & (2) & \text { oxide ion formation } \\
& \rightarrow \mathrm{R}^{\prime^{-}}+\mathrm{H}_{2} \mathrm{O} & \text { (3) } & \mathrm{H}_{2}^{+} & \text {abstraction } \\
& \rightarrow \mathrm{R}^{-}+\mathrm{OH} & \text { (4) } & \mathrm{H}^{+} & \text {abstraction }
\end{array}
$$

Since the development of SIFT (selected ion flow tube) technique by Deputy et al. ${ }^{[8,9]}$, extensive experimental studies have been conducted on reactions between $\mathrm{O}^{-}$and neutral molecules. In reactions between $\mathrm{O}^{-}$and halogenated compounds, the existence of the above mentioned four channels were confirmed by detecting all anion products and measuring their branching ratios ${ }^{[10-15]}$. Yamamoto et al. ${ }^{[16]}$ investigated the reaction mechanism between $\mathrm{O}^{-}$anion and $\mathrm{CH}_{3} \mathrm{~F}$ at the density functional theory (DFT) level. Their results implied that these reaction rates were determined by the dipole moments of halogenated methane such as $\mathrm{CH}_{3} \mathrm{~F}, \mathrm{CH}_{2} \mathrm{~F}_{2}$, and $\mathrm{CHF}_{3}$.

The reaction between $\mathrm{O}^{-}$anion and benzene has been investigated using a variety of experimental techniques because important intermediate anions, $\mathrm{C}_{6} \mathrm{H}_{5} \mathrm{O}^{-}$and $\mathrm{C}_{6} \mathrm{H}_{5}^{-}$, can be potentially generated. Stockdale et al. ${ }^{[17]}$ first studied this reaction in 1970. $\mathrm{O}^{-}$anions were generated via dissociative electron attachment (DEA) technique, and were then reacted with benzene in gas cell. All anion products were observed using a TOF mass spectrometer, and the branching ratios were detected: $\mathrm{C}_{6} \mathrm{H}_{4}^{-}+\mathrm{H}_{2} \mathrm{O} \quad 57 \%, \mathrm{C}_{6} \mathrm{H}_{5} \mathrm{O}^{-}+\mathrm{H} \quad 43 \%, \mathrm{C}_{6} \mathrm{H}_{5}+\mathrm{OH}^{-}<1 \%$. Subsequently, Futrell et al. ${ }^{[18]}$ used similar experimental technique to reinvestigate this reaction, and the major anion products were $\mathrm{C}_{6} \mathrm{H}_{4} 42 \%, \mathrm{C}_{6} \mathrm{H}_{5} \mathrm{O}^{-} 25 \%$, and $\mathrm{OH}^{-} 33 \%$. By using 
double-focusing mass spectrometer, Bruins et al ${ }^{[19]}$ obtained the branching ratio of $\mathrm{C}_{6} \mathrm{H}_{5} \mathrm{O}^{-}$, which was nearly twice as that of $\mathrm{C}_{6} \mathrm{H}_{4}^{-}$. The subsequent experimental branching ratios were slightly different: $\mathrm{C}_{6} \mathrm{H}_{4}^{-} 48 \%, \mathrm{C}_{6} \mathrm{H}_{5} \mathrm{O}^{-} 39 \%$, and $\mathrm{OH}^{-} 13 \%{ }^{[20]}$. Obviously, results obtained using different experimental techniques and conditions differ from each other. Therefore, it is necessary to explore the mechanism for this reaction using high-level theoretical calculations. As per the available information, there has been no theoretical work published to understand mechanism of the title reaction.

In this article, quantum chemical calculations are used to explore the mechanism of the title reaction. All possible reaction products are deduced based on the calculations and thermodynamics analysis that has been employed in this study. Barrier heights are determined to qualitatively understand the validity of product pathways. Different experimental conclusions are explained subsequently. A valid and clear mechanism for the title reaction is proposed to give insight into studying similar reactions.

\section{Computational methods}

According to the negative charge and typical open-shell electric configurations involved in the title reaction, the spin contamination is a serious problem. Therefore, the DFTB3LYP method is applied to study this reaction, as the previous study showed that the B3LYP method exhibited good performance while dealing with this type of open-shell system ${ }^{[16]}$.

Optimized geometries of all reactants, products, complexes (denoted as $\mathrm{CM}$ ), transition states (denoted as TS), vibrational frequencies, and zero-point energies (ZPEs) are calculated using the B3LYP method. To consider the diffuse electron effects involved in the title reaction system, polarized and diffuse functions are expanded to the standard basis set $6-31 \mathrm{G}(d)$ as the $6-31+\mathrm{G}(d, p)$ basis set to study the expansive basis set effects. In addition, intrinsic-reaction-coordinate (IRC) calculations are performed to clarify every transition state as well as the corresponding reactant and product. Meanwhile, the electron-transfer mechanisms along the minimum-energy paths (MEP) can also be shown. The previous studies ${ }^{[21-23]}$ suggested that the G2MP2 method ${ }^{[24]}$ was suitable and accurate for the study of open-shell systems. Therefore, the G2MP2 method is performed to calculate the single-point energies of all species with the $\mathrm{B} 3 \mathrm{LYP} / 6-31+\mathrm{G}(d, p)$ optimized geometries and to calculate relative energies as well as reaction enthalpies, and then the results obtained are compared with those of the previous experiments. To estimate the spin contamination effect, the UMP2 energies are substituted for the projected MP2 energies. In addition, the ZPEs and temperature corrections are obtained with the $\mathrm{B} 3 \mathrm{LYP} / 6-31+\mathrm{G}(d, p)$ vibrational frequencies. All the above calculations are carried out using the Gaussian-03 program package ${ }^{[25]}$.

\section{Computational results}

Due to the $\pi$-bond conjugate of the benzene, the hexahydroxy cycle is partially electronegative, whereas the hydrogen atoms are partially electropositive. As a result of the charge induction effect, the $\mathrm{O}-\mathrm{H}$ bond is most probably formed, while the anion $\mathrm{O}^{-}$approaches the benzene molecule to form an initial complex, which can further decompose and/or isomerize to various kinds of species. On the basis of this assumption, the B3LYP calculations have been carried out to obtain optimized geometries. There are no obvious differences between the results with the $6-31 \mathrm{G}(d)$ and $6-31+\mathrm{G}(d, p)$ basis sets, which suggests a less severe diffuse electron effect in the title reaction system. So, only optimized structures of the B3LYP/6-31+ $\mathrm{G}(d, p)$ method are shown in Fig.1, where the imaginary vibration modes are also presented. Meanwhile, all spin-squared expectation values $\left\langle S^{2}\right\rangle$ for all doublets are in the range of $0.750-0.782$, indicating that spin contamination is not severe. Finally, the G2MP2 energies are listed in Table 1. Reaction mechanisms and relative energies are shown in Fig.2. In Table 1, the calculated reaction enthalpies are consistent with those obtained in experimental results ${ }^{[26-29]}$, and errors are less than $18 \mathrm{~kJ} \cdot \mathrm{mol}^{-1}$. Thus, the present method is suitable to investigate the title reaction system.

Hodgson et al.'s results ${ }^{[30]}$ have pointed out that a neutral oxygen atom will attach to the carbon atom via a small barrier
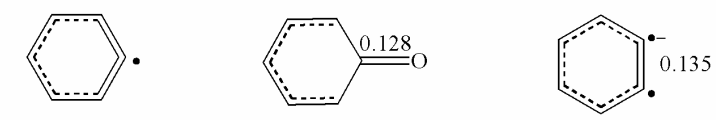

$\mathrm{C}_{6} \mathrm{H}_{5}$

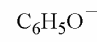

$\mathrm{C}_{6} \mathrm{H}_{4}^{-}$
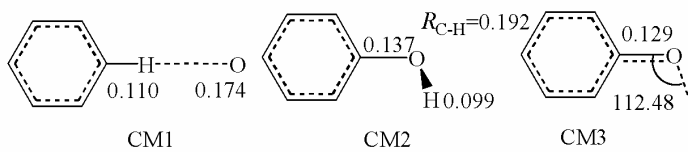

$\mathrm{CM}$

$\mathrm{CM}$

$\mathrm{CM} 2$

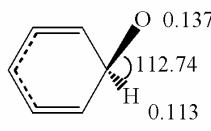

$0.102-0.097$

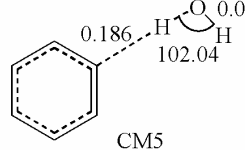

$\mathrm{CM} 4$

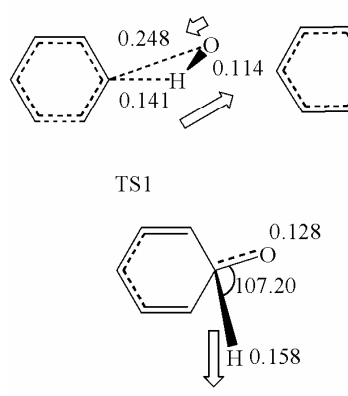

TS4

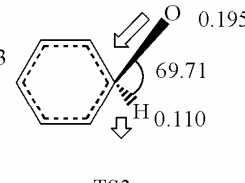

TS3

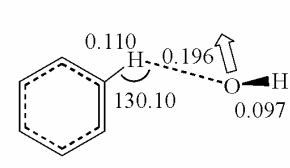

TS5

Fig.1 The optimized structures of main species at the $\mathrm{B} 3 \mathrm{LYP} / 6-31+\mathrm{G}(d, p)$ level bond length in $\mathrm{nm}$, bond angle in degree 
Table 1 Total energies, relative energies, reaction enthalpies, and $\mathrm{ZPE}$ of main species

\begin{tabular}{|c|c|c|c|c|c|}
\hline Species & $v_{\mathrm{i}}^{\mathrm{a}} / \mathrm{cm}^{-1}$ & $\begin{array}{c}\text { ZPE } \\
\left(_{(\text {hartree })}\right.\end{array}$ & $\begin{array}{c}-E_{0}[\mathrm{G} 2 \mathrm{MP} 2] \\
\text { (hartree) }\end{array}$ & $\frac{\Delta E_{0}^{\Theta}}{\mathrm{kJ} \cdot \mathrm{mol}^{-1}}$ & $\begin{array}{r}\Delta_{\mathrm{r}} H_{298}^{\ominus} \\
\mathrm{kJ} \cdot \mathrm{mol}^{-1}\end{array}$ \\
\hline $\mathrm{C}_{6} \mathrm{H}_{6}+\mathrm{O}^{-}$ & & 0.09541 & 306.80443 & 0.0 & 0.0 \\
\hline $\mathrm{C}_{6} \mathrm{H}_{5} \mathrm{O}^{-}+\mathrm{H}$ & & 0.08588 & 306.86499 & -159.0 & $\begin{array}{l}-159.4 \\
-142.3^{\mathrm{c}}\end{array}$ \\
\hline $\mathrm{C}_{6} \mathrm{H}_{4}^{-}+\mathrm{H}_{2} \mathrm{O}$ & & 0.08949 & 306.82054 & -42.6 & $\begin{array}{l}-39.1 \\
-43.9^{\mathrm{c}}\end{array}$ \\
\hline $\mathrm{C}_{6} \mathrm{H}_{5}+\mathrm{OH}^{-}$ & & 0.09104 & 306.80193 & 6.6 & $\begin{array}{r}9.5 \\
11.3^{\mathrm{c}}\end{array}$ \\
\hline $\mathrm{C}_{6} \mathrm{H}_{5}^{-}+\mathrm{OH}$ & & 0.08895 & 306.78240 & 57.8 & $\begin{array}{l}60.4 \\
77.4^{\mathrm{c}}\end{array}$ \\
\hline CM1 & & 0.09706 & 306.82627 & -57.3 & \\
\hline $\mathrm{CM} 2$ & & 0.09465 & 306.87716 & -191.0 & \\
\hline CM3 & & 0.08851 & 306.86686 & -163.9 & \\
\hline $\mathrm{CM} 4$ & & 0.09331 & 306.85757 & -139.5 & \\
\hline CM5 & & 0.09160 & 306.84436 & -104.9 & \\
\hline TS1 & $1047 i$ & 0.08786 & 306.81921 & -38.8 & \\
\hline TS2 & $808 i$ & 0.08811 & 306.86519 & -159.5 & \\
\hline TS3 & $336 i$ & 0.09362 & 306.81527 & -28.5 & \\
\hline TS4 & $940 i$ & 0.08785 & 306.84798 & -114.3 & \\
\hline TS5 & $135 i$ & 0.09135 & 306.83199 & -72.3 & \\
\hline
\end{tabular}

a) calculated at the $\mathrm{B} 3 \mathrm{LYP} / 6-31+\mathrm{G}(d, p)$ level; b) zero-point energy calculated with the calculated vibrational frequencies (scaled by $0.95^{[28]}$ );

c) experimental values from Ref.[29-31]

to form the initial intermediate while approaching the benzene molecule. The B3LYP calculations that have been described in this study have shown the totally different entrance potential surface of the $\mathrm{O}^{-}+\mathrm{C}_{6} \mathrm{H}_{6}$ reaction, compared with that of the $\mathrm{O}+\mathrm{C}_{6} \mathrm{H}_{6}$ reaction. Among all the possible spatial approach directions, the most favorable path for $\mathrm{O}^{-}$close to the benzene molecule is along the $\mathrm{C}-\mathrm{H}$ bond to form the initial complex $\left[\mathrm{C}_{6} \mathrm{H}_{6} \cdots \mathrm{O}\right]^{-}$(CM1). As shown in Fig.1, the active $\mathrm{C}-\mathrm{H}$ bond length of CM1 is $0.110 \mathrm{~nm}$, and it is very close to that of the benzene molecule; the distance between the attacked $\mathrm{H}$ and $\mathrm{O}$ atoms is $0.174 \mathrm{~nm}$, just slightly shorter than a normal hydro-

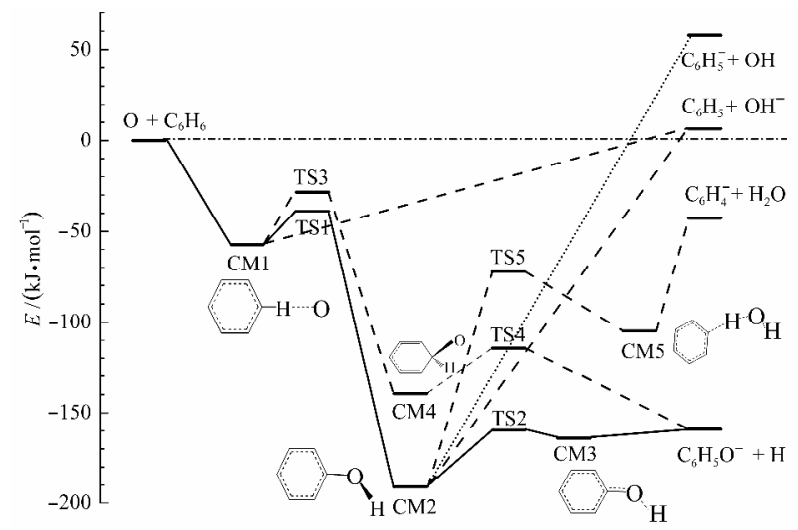

Fig.2 The scheme of relative energies for the $\mathrm{O}^{-}+\mathrm{C}_{6} \mathrm{H}_{6}$ reaction gen bond length; meanwhile, Mulliken atomic-charge analysis suggests that the negative charge is predominantly restricted to that of the $\mathrm{O}$ atom. Thus, the interaction between $\mathrm{O}$ atom and the benzene ring in CM1 is strengthened due to the charge attractive effect. CM1 has an available energy of $57.3 \mathrm{~kJ} \cdot \mathrm{mol}^{-1}$ relative to the initial reactants, and can easily further decompose and/or isomerize to various species. It should be noticed that all atoms are kept in a plane in the combination process, and CM1 has a $C_{s}$ point group with the ${ }^{2} A$ ' symmetry. When further decomposition and/or isomerization take place, the plane structure may be destroyed via four possible product channels: hydrogen abstraction (1), oxide ion formation (2), $\mathrm{H}_{2}^{+}$abstraction (3), and proton abstraction (4), which will be discussed separated in the following sections.

\subsection{Hydrogen abstraction channel (1)}

As shown in Fig.2, CM1 can decompose to $\mathrm{C}_{6} \mathrm{H}_{5}$ and $\mathrm{OH}^{-}$directly, with an endothermic energy of $63.9 \mathrm{~kJ} \cdot \mathrm{mol}^{-1}$. The corresponding overall process is endothermic by 6.6 $\mathrm{kJ} \cdot \mathrm{mol}^{-1}$. So this channel is not favorable. To understand the abstraction process in detail, the stepped-optimization method has been performed to monitor the change of geometries and energies. Based on the $\mathrm{B} 3 \mathrm{LYP} / 6-31+\mathrm{G}(d, p)$ results, no obvious energy barrier has been found. With the increase in $\mathrm{C}-\mathrm{H}$ bond length, the distance between $\mathrm{O}^{-}$and $\mathrm{H}$ atoms is reduced to form a $\sigma$ bond, whereas the energy of system increases close to the total energy of the abstraction products. When the $\mathrm{O}-\mathrm{H}$ bond length is decreased to $0.099 \mathrm{~nm}$, close to the equilibrium bond length of $\mathrm{OH}^{-}$anion, the Mulliken atomic charge on $\mathrm{O}$ atom is -0.64 . Therefore, the decomposition product of $\mathrm{CM} 1$ is the $\mathrm{OH}^{-}$anion rather than the neutral $\mathrm{OH}$ radical. In contrast to the $\mathrm{H}$-abstraction channel in the $\mathrm{O}^{-}+\mathrm{CH}_{3} \mathrm{~F}$ reaction $^{[16]}$, no product complex has been found on the exit potential energy surface at the B3LYP/6-31+G $(d, p)$ level.

$\mathrm{CM} 1$ can also isomerize to phenol anion and subsequently dissociate to $\mathrm{OH}^{-}$and $\mathrm{C}_{6} \mathrm{H}_{5}$. First, the $\mathrm{O}$ atom in $\mathrm{CM} 1$ can attach to the active $\mathrm{C}$ atom via a transition state $\mathrm{TS} 1$, when the active $\mathrm{O}-\mathrm{H}$ bond is broken and the $\mathrm{C}-\mathrm{O}$ and $\mathrm{O}-\mathrm{H}$ bonds are formed. A complex CM2, phenol anion is formed. This isomerization is just similar to the typical insertion reaction process $^{[21,22]}$. The TS1 has a loose triatomic-ring structure: the distances between $\mathrm{C}-\mathrm{H}, \mathrm{O}-\mathrm{H}$, and $\mathrm{O}-\mathrm{C}$ are $0.141 \mathrm{~nm}, 0.114 \mathrm{~nm}$, and $0.248 \mathrm{~nm}$, respectively, as shown in Fig.1. Meanwhile, the Mulliken atomic charges on the $\mathrm{C}$ and $\mathrm{O}$ atoms are -0.28 and -0.84 , respectively. Thus, as $\mathrm{O}$ approaches $\mathrm{C}$, the electronic repulsion between the $\mathrm{O}$ and $\mathrm{C}$ atoms increases the energy of TS1 with their distance decreasing, and the barrier energy is $18.5 \mathrm{~kJ} \cdot \mathrm{mol}^{-1}$ higher than that of the CM1 but still lower than the energy of the initial reactants. In contrast to the hydrogen bond complex CM1, the CM2 is a stable anion intermediate (phenol anion), and all bonds are stable chemical bonds. Therefore, the energy of CM2 is far lower than that of the ini- 
tial reactants, $191.0 \mathrm{~kJ} \cdot \mathrm{mol}^{-1}$, so its high active energy can lead to further isomerization or dissociation. It should be noted that the $\mathrm{O}$ atom of $\mathrm{CM} 2$ has a small negative charge of 0.184 , rather smaller than that of CM1. It implies that this isomerization process is coupled with charge transfer. In fact, the conjugate action between the $p$-orbital of $\mathrm{O}$ atom and $\pi$-bond of benzene cycle favors charge transfer. The Mulliken atomic-charge analysis along MEP has estimated this negative charge transfer as shown in Fig.3.

Similarly, CM2 can directly decompose to $\mathrm{H}$-abstraction products $\mathrm{C}_{6} \mathrm{H}_{5}$ and $\mathrm{OH}^{-}$, and no barrier has been found at the $\mathrm{B} 3 \mathrm{LYP} / 6-31+\mathrm{G}(d, p)$ level. Although mostly localized on the $\pi$-bond of benzene ring in $\mathrm{CM} 2$, the negative charge relocalizes and gradually transfers to the $\mathrm{OH}$ group as the decomposition progresses. Finally, the Mulliken atomic-charge analysis shows that the anionic product of this bond decomposition is $\mathrm{OH}^{-}$instead of $\mathrm{C}_{6} \mathrm{H}_{5}^{-}$. Due to the stronger $\mathrm{C}-\mathrm{O}$ bond and the conjugate action between $\mathrm{O}$ atom and benzene ring, this process is far endothermic by $197.5 \mathrm{~kJ} \cdot \mathrm{mol}^{-1}$.

\subsection{The oxide ion formation channel (2)}

The isomerization and decomposition are needed for CM1 to produce $\mathrm{C}_{6} \mathrm{H}_{5} \mathrm{O}^{-}$and $\mathrm{H}$. The calculation that has been described in this study has shown two possible reaction pathways in Fig.2.

In contrast to the neutral phenol molecule, the $\mathrm{H}$ atom in $\mathrm{CM} 2$ anion is repulsed out of the benzene plane by the conjugate electron cloud. Therefore, the $\mathrm{O}-\mathrm{H}$ bond is weakened slightly and can dissociate to produce the $\mathrm{H}$ atom via a 31.4 $\mathrm{kJ} \cdot \mathrm{mol}^{-1}$ barrier, TS2. The TS2 is a typical product-like barrier, and its energy is close to that of products. In the geometry of $\mathrm{TS} 2$, the $\mathrm{O}-\mathrm{H}$ bond is elongated to $0.146 \mathrm{~nm}$, and the $\mathrm{C}-\mathrm{H}$ bond shortened to $0.130 \mathrm{~nm}$, close to the bond length of $\mathrm{C}=\mathrm{O}$ in the product $\mathrm{C}_{6} \mathrm{H}_{5} \mathrm{O}^{-}, 0.128 \mathrm{~nm}$. The detailed B3LYP calculation implies that there is a complex $\mathrm{CM} 3\left[\mathrm{C}_{6} \mathrm{H}_{5} \mathrm{O}^{-} \cdots \mathrm{H}\right]$ in the exit potential surface, in which the distance between $\mathrm{H}$ and $\mathrm{O}$ atoms is $0.180 \mathrm{~nm}$, corresponding to a classical hydrogen bond length.

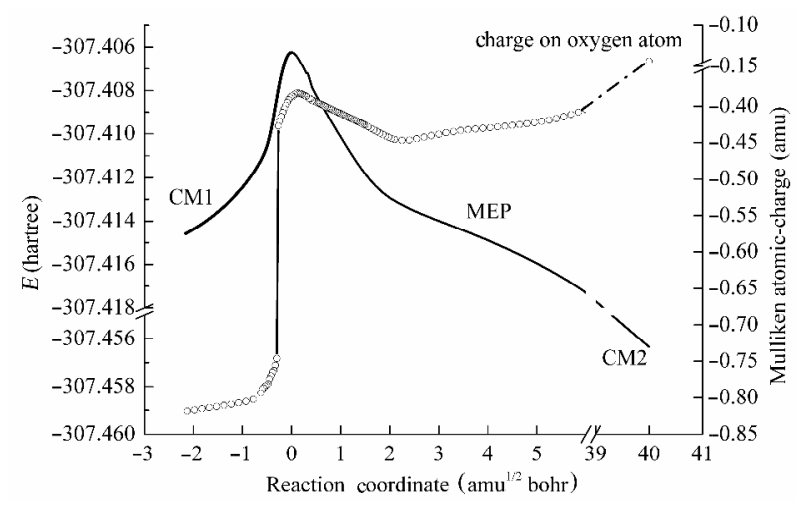

Fig.3 The MEP and Mulliken atomic-charge analysis for the $\mathrm{CM} 1$ to $\mathrm{CM} 2$ isomerization
The other product pathway corresponds to isomerization from CM1 to CM4 via a transition state TS3. O atom attaches benzene from outside plane and is bonded to active $\mathrm{C}$ atom; meanwhile, the $\mathrm{H}$ atom connected with the $\mathrm{C}$ atom is pushed outside the benzene plane. Obviously, the $\pi$-bond of benzene ring is broken down in this process, so that the TS3 is relatively high, $28.9 \mathrm{~kJ} \cdot \mathrm{mol}^{-1}$ but still lower than the reactants. Therefore, this isomerization process is thermodynamically favorable. The $\mathrm{C}-\mathrm{O}$ bond in $\mathrm{CM} 4$ is rapidly shortened from $0.195 \mathrm{~nm}$ in $\mathrm{CM} 3$ to $0.137 \mathrm{~nm}$, and $\angle \mathrm{OCH}$ enlarged from $69.71^{\circ}$ in TS3 to $112.74^{\circ}$ by steric hindrance. The benzene cycle is slightly loosened, with the $\mathrm{C}-\mathrm{C}$ bond including the active $\mathrm{C}$ atom elongated to $0.152 \mathrm{~nm}$. Therefore, the active $\mathrm{C}$ atom in CM4 has changed from $s p^{2}$ to $s p^{3}$ hybrid, while all chemical bonds are close to single bond, and the negative charge is distributed mostly among benzene ring and $\mathrm{O}$ atom, with the charge of -0.684 on $\mathrm{O}$ atom. Obviously, the conjugate $\pi$-bond structure in benzene has been broken, thus CM4 has a higher energy than CM2. However, its energy is still far lower than that of the initial reactants by $139.5 \mathrm{~kJ} \cdot \mathrm{mol}^{-1}$ and can furthermore decompose to $\mathrm{C}_{6} \mathrm{H}_{5} \mathrm{O}^{-}$and $\mathrm{H}$ via a barrier TS4. In this decomposition process, the $\mathrm{C}-\mathrm{H}$ bond is elongated from $0.113 \mathrm{~nm}$ in CM4 to $0.158 \mathrm{~nm}$ in TS4, and $\mathrm{C}-\mathrm{O}$ bond is shortened to $0.128 \mathrm{~nm}$. The imaginary vibration mode of TS4 corresponds to the stretching vibration of the decomposing $\mathrm{C}-\mathrm{H}$ bond. Structure of the $\left[\mathrm{C}_{6} \mathrm{H}_{5} \mathrm{O}^{-}\right]$part in TS4 is very close to that of product anion $\mathrm{C}_{6} \mathrm{H}_{5} \mathrm{O}^{-}$, indicating that TS4 is also a late barrier. The decomposition pathway is exothermic by $19.5 \mathrm{~kJ} \cdot \mathrm{mol}^{-1}$ relative to CM4. No stable complex has been found by the present calculation with regard to the exit potential surface, compared with that associated with the decomposition of CM2.

\section{$2.3 \quad \mathrm{H}_{2}^{+}$-abstraction channel (3)}

$\mathrm{H}_{2} \mathrm{O}$ as the product of the $\mathrm{H}_{2}^{+}$-abstraction channel has been detected in previous experiments involving reactions of $\mathrm{O}^{-}$ with molecules containing hydrogen. According to the entrance reaction potential surface and the structure of CM1, it is certain that $\mathrm{H}_{2}^{+}$abstraction must occur via either a concerted decomposition of two hydrogen atoms or multistep isomerization. There must be a five-element ring transition state with high energy in a concerted dissociation process. No such transition state has been located on this B3LYP potential energy surface.

The present calculation has clarified that $\mathrm{CM} 1$ can produce $\mathrm{H}_{2} \mathrm{O}$ finally via two isomerization steps. First, $\mathrm{H}$ is transferred on isomerization from $\mathrm{CM} 1$ to $\mathrm{CM} 2$; second, $\mathrm{OH}$ group of CM2 is transferred, and CM5 $\left[\mathrm{C}_{6} \mathrm{H}_{4}^{-} \cdots \mathrm{H}_{2} \mathrm{O}\right]$ is formed via a barrier TS5. The first step of isomerization is the same as that in the oxide ion formation channel (2), whereas the second process has a high barrier TS5, $118.7 \mathrm{~kJ} \cdot \mathrm{mol}^{-1}$. As shown in Fig.1, the imaginary vibration mode of TS5 mainly corre- 
sponds to the translation movement of $\mathrm{OH}$ group to the neighboring $\mathrm{H}$, with a small imaginary frequency of $135 \mathrm{~cm}^{-1}$, indicating that the TS5 is a loose barrier. IRC calculation has confirmed that the TS5 exactly links CM2 and CM5. That is, $\mathrm{OH}$ group of $\mathrm{CM} 2$ approaches the neighboring $\mathrm{C}-\mathrm{H}$ generally, and the $\mathrm{O}$ atom is bonded to the $\mathrm{H}$ atom when the $\mathrm{C}-\mathrm{H}$ bond is broken. In the structure of CM5 shown in Fig.1, the $\mathrm{C}-\mathrm{O}$ bond is completely broken, and the distance between $\mathrm{O}$ and the neighboring $\mathrm{H}$ is shortened to $0.196 \mathrm{~nm}$ to form a typical hydrogen bond. As the transfer progresses, the $\mathrm{C}-\mathrm{H}$ bond is elongated promptly to $0.186 \mathrm{~nm}$, and the distance between $\mathrm{O}$ and $\mathrm{H}$ atoms is shortened to $0.102 \mathrm{~nm}$ to form a $\sigma$ bond, and subsequently the anion complex CM5 is formed. The $\mathrm{H}_{2} \mathrm{O}$ group in CM5 is very similar to that of the neutral $\mathrm{H}_{2} \mathrm{O}$ molecule, whereas the structure of the other part $\left[\mathrm{C}_{6} \mathrm{H}_{4}^{-}\right]$is close to that of the product $\mathrm{C}_{6} \mathrm{H}_{4}^{-}$. Finally, CM5 can decompose directly to $\mathrm{C}_{6} \mathrm{H}_{4}^{-}$and $\mathrm{H}_{2} \mathrm{O}$. Although the barrier involved in this reaction pathway is relatively high, its energy is still below that of the initial reactants, and the overall reaction pathway is favorable in energetics with an exothermic energy of 42.6 $\mathrm{kJ} \cdot \mathrm{mol}^{-1}$.

\subsection{The $\mathbf{H}^{+}$-abstraction channel (4)}

The product pathway corresponding to $\mathrm{C}_{6} \mathrm{H}_{5}^{-}$and $\mathrm{OH}$ products has not been found. In view of the structures of species involved, the $\mathrm{H}^{+}$-abstraction reaction is the most favorable reaction pathway for CM2 anion. However, the H-abstraction reaction is the other product channel with an apparently lower barrier as shown in Fig.2. Thus, a possible transition state of channel (4) probably crosses with exited states of other product channels on potential energy surface. Moreover, the point group of the species involved in this channel is $C_{1}$, so that no symmetry restraint makes that these potential surfaces could not be distinguished at the B3LYP level. Therefore, the possible pathway for channel (4) is represented as a broken line in Fig.2.

\subsection{Comparison with experimental results}

The present calculations have shown that the oxide ion formation channel, $\mathrm{O}^{-}+\mathrm{C}_{6} \mathrm{H}_{5} \rightarrow \mathrm{CM} 1 \rightarrow \mathrm{TS} 1 \rightarrow \mathrm{CM} 2 \rightarrow$ TS2 $\rightarrow \mathrm{CM} 3 \rightarrow \mathrm{C}_{6} \mathrm{H}_{5} \mathrm{O}^{-}+\mathrm{H}$, is the most favorable among all the reaction pathways. In addition, the $\mathrm{H}_{2}^{+}$-abstraction channel (3) is also possible in thermodynamics, and $\mathrm{H}$-abstraction (1) and $\mathrm{H}^{+}$-abstraction (4) are difficult to occur. More detailed chemical-reaction kinetic calculations, e.g. RRKM, could show branching ratios of all corresponding product channels. The above conclusions are consistent with most those obtained in previous experimental results, that is, $\mathrm{C}_{6} \mathrm{H}_{5} \mathrm{O}^{-}+\mathrm{H}$ and $\mathrm{C}_{6} \mathrm{H}_{4}^{-}+\mathrm{H}_{2} \mathrm{O}$ are major products.

However, Stockdale ${ }^{[17]}$, Futrell ${ }^{[18]}$, and Vanorden ${ }^{[19]}$ detected more number of $\mathrm{C}_{6} \mathrm{H}_{4}^{-}$anions than $\mathrm{C}_{6} \mathrm{H}_{5} \mathrm{O}^{-}$anions in their SIFT experiments, whereas Bruins observed contrary results.
The calculations in this study suggest that the latter experimental conclusion is in closer agreement to the real situation. In the experiments of Stockdale et al. ${ }^{[4]}, \mathrm{O}^{-}$anion was generated via DEA (dissociative electron attachment), with higher translation energy of $2 \mathrm{eV}$. Thus, the entire reaction system had a higher initial energy. Those endothermic reactions, $\mathrm{H}$-abstraction and $\mathrm{H}^{+}$-abstraction, became favorable. Therefore, the observed branching ratio is far different from the present result at the zero-translation energy level, and a little amount of $\mathrm{OH}^{-}$anion observed as reaction product was qualitatively valid ${ }^{[20]}$. As shown in Fig.2, both $\mathrm{C}_{6} \mathrm{H}_{5} \mathrm{O}^{-}$and $\mathrm{C}_{6} \mathrm{H}_{4}^{-}$ mainly result from decomposition and isomerization of $\mathrm{CM} 2$. Therefore, the branching ratio is only determined by the properties of TS2 and TS5. Although TS5 has higher energy than TS2, its frequencies are far smaller than those of TS2. The microcanonical rate constant $k(E)$ in chemical dynamics theory $^{[31]}$ is

$$
k(E)=\frac{N^{\mathrm{TS}}\left(E-E^{\neq}\right)}{h \rho^{\mathrm{R}}(E)}
$$

Where $N^{\mathrm{TS}}\left(E-E^{\ddagger}\right)$ and $\rho^{\mathrm{R}}(E)$ are the sum of states and density of states of TS and CM, respectively. Thus, when the initial energy of reaction system is high enough, the sum of states of TS5 exceeds that of TS2 by a large extent, and the branching ratio of channel corresponding to TS5 is higher compared to that of TS2.

On the other hand, most previous experiments were completed in gas cell ${ }^{[4]}$ with a pressure of about $1.33 \times 10^{4} \mathrm{~Pa}$, where anion products were generated, and further reactions might change the concentrations of the observed anion species. Among the anion products of $\mathrm{C}_{6} \mathrm{H}_{5} \mathrm{O}^{-}, \mathrm{C}_{6} \mathrm{H}_{4}^{-}$, and $\mathrm{OH}^{-}, \mathrm{OH}^{-}$ can react with benzene rapidly to generate $\mathrm{C}_{6} \mathrm{H}_{4}^{-}$and $\mathrm{H}_{2} \mathrm{O}^{[4]}$. Thus, $\mathrm{C}_{6} \mathrm{H}_{4}^{-}$signal is increased distinctly when $\mathrm{OH}^{-}$is decreased. Moreover, $\mathrm{C}_{6} \mathrm{H}_{5} \mathrm{O}^{-}$anion is also active to a certain extent and probably reacts with buffer gas or water, and this leads to the underestimation of its signal that has been observed in previous experiments.

\section{Conclusions}

The reaction mechanism between atomic oxygen-radical anion and benzene has been investigated using the density functional theory (DFT). Geometries of the reactants, products, complexes, and transition states involved have been optimized at the $\mathrm{B} 3 \mathrm{LYP} / 6-31+\mathrm{G}(d, p)$ level, and their vibrational frequencies and zero-point energies (ZPEs) have been calculated subsequently at the same level. The multichannel pathways, the $\mathrm{H}$ abstraction (1), oxide ion formation (2), $\mathrm{H}_{2}^{+}$abstraction (3), and proton abstraction (4), are confirmed. Their relative energies are obtained at the G2MP2 level to ensure barrier heights, and then the branching ratios of all the product channels are analyzed qualitatively. It is shown that oxide ion formation (2) and $\mathrm{H}_{2}^{+}$abstraction (3) are major product channels, whereas $\mathrm{H}$ abstraction (1) and proton abstraction (4) are not 
favorable product channels. Validity and inconsistency of previous experimental results are confirmed and interpreted in the view of barrier height. A clear reaction process has been established for the title reaction.

\section{References}

1 Bowers, M. T. Gas phase ion chemistry. New York: Academic Press, 1984

2 Wayne, R. P. Chemistry of atmosphere. Oxford: Clarendon Press, 1991

3 Valentine, J. Active oxygen in biochemistry. London: Blackie Acad. \& Profes. Press, 1995

4 Lee, J.; Grabowski, J. J. Chem. Rev., 1992, 92: 1611

5 Che, M.; Tench, A. J. J. Adv. Catal., 1983, 32: 1

6 Fehsenfeld, F.; Ferguson, E.; Schmeltekopf, A. J. Chem. Phys., 1966, 45: 1844

7 Arnold, F.; Kissel, J.; Krankowsky, D.; Wieder, H.; Zahringer, J. J. Atoms. Terr. Phys., 1971, 33: 1169

8 Bierbaum, V.; Depuy, C. H.; Shapiro, R. H.; Stewart, J. H. J. Am. Chem. Soc., 1976, 98: 4229

9 van Doren, J. M.; Barlow, S. E.; Depuy, C. H.; Bierbaum, V. M. J. Am. Chem. Soc., 1987, 109: 4412

10 Peverall, R.; Kennedy, R. A.; Mayhew, C. A.; Watts, P. Int. J. Mass Spectrom. Ion Processes, 1997, 171: 51

11 Mayhew, C. A.; Peverall, R.; Watts, P. Int. J. Mass Spectrom. Ion Processes, 1993, 54: 1643

12 Tanaka, K.; Mackay, G. I.; Payzant, J. D.; Bohme, D. K. Can. J. Chem., 1976, 54: 1643

13 Streit, G. E. J. Phys. Chem., 1982, 86: 2321

14 Morris, R. A.; Viggiano, A. A.; Arnold, S. T.; Liebman, J. F. J. Phys. Chem., 1995, 99: 5992

15 Dawson, J.; Jennings, K. J. Chem. Soc. Faraday Trans., 1976, 272:
700

16 Yamamoto, M.; Yamashita, K.; Sadakata, M. J. Mole. Struc. (TheoChem), 2003, 634: 31

17 Stockdale, J. A. D.; Compton, R. N.; Reinhardt, P. W. Int. J. Mass Spectom. Ion Phys., 1970, 4: 401

18 Futrell, J. H.; Tiernan, T. O. Ion-molecule reactions. Vol.2. New York: Lenum Press, 1972

19 Bruins, A. P.; Correia, A. J.; Harrison, A. G.; Jennings, K. R.; Mitchum, R. K. Adv. Mass. Spectrom., 1978, 7: 355

20 Vanorden, S. L.; Malcomson, M. E.; Buckner, S. W. Anal. Chim. Acta, 1991, 246: 199

21 Zhou, X.; Pei, L.; Zhang, L.; Dai, J.; Chen, Y.; Yu, S.; Ma, X. Chem. Phys., 2002, 279: 15

22 Zhou, X.; Yu, S.; Li, J.; Sheng, Z.; Zhang, L.; Ma, X. Chem. Phys. Lett., 2001, 339: 117

23 Zhou, X.; Li, J.; Zhao, X.; Tian, Y.; Zhang, L.; Chen, Y.; Chen, C.; Yu, S.; Ma, X. Phys. Chem. Chem. Phys., 2001, 3: 3662

24 Curtiss, L. A.; Raghavachari, K.; Pople, J. A. J. Chem. Phys., 1993, 98: 1293

25 Frisch, M. J.; Trucks, G. W.; Schlegel, H. B.; et. al. Gaussian 2003. Reversion B. 05. Pittsburgh PA: Gaussian Inc., 2003

26 Chase, M. W.; Davies, C. A.; Downey, J. R.; Frurip, D. J.; McDonald, R. A.; Syverud, A. N. J. Phys. Chem. Ref. Data, 1985, 14(suppl): 1

27 Chase, M. W. J. Phys. Chem. Ref. Data, 1998, 1: 1951

28 Foresman, J. B.; Frisch, E. Exploring chemistry with electronic structure methods. 2nd ed. Pittsburgh PA: Gaussian Inc., 1998

29 Prosen, E. J.; Gilmont, R.; Rossini, F. D. J. Res. NBS, 1945, 34: 65

30 Hodgson, D.; Zhang, H.; Nimlos, M.; McKinnon, J. J. Phys. Chem., 2001, 105: 4316

31 Gilbert, R. G.; Smith, S. C. Theory of unimolecular and recombination reactions. London: Blackwell Press, 1990 